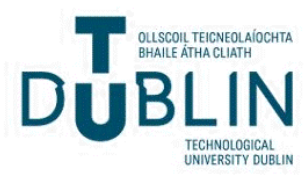

Technological University Dublin

ARROW@TU Dublin

2014-11-06

\section{Printed Triple-Band Circularly Polarised Antenna for Wireless Systems}

\author{
Xiulong Bao \\ Technological University Dublin, xiulong.bao@tudublin.ie \\ Max Ammann \\ Technological University Dublin, max.ammann@tudublin.ie
}

Follow this and additional works at: https://arrow.tudublin.ie/engscheceart

Part of the Electrical and Electronics Commons

\section{Recommended Citation}

Bao, Z . \& Ammann, M. (2014) Printed Triple-Band Circularly Polarised Antenna for Wireless Systems, Electronic letters 6th November, Vol. 50 No. 23 pp. 1664-1665 http://dx.doi.org/10.1049/el.2014.3103

This Article is brought to you for free and open access by the School of Electrical and Electronic Engineering at ARROW@TU Dublin. It has been accepted for inclusion in Articles by an authorized administrator of ARROW@TU Dublin. For more information, please contact arrow.admin@tudublin.ie, aisling.coyne@tudublin.ie, gerard.connolly@tudublin.ie.

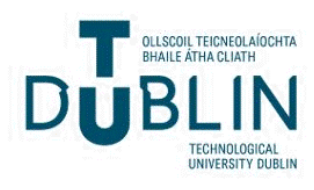




\section{Printed triple-band circularly polarised antenna for wireless systems}

\section{X.L. Bao and M.J. Ammann}

A triple-band circularly polarised microstrip patch antenna operating in the $2.4,3.5$ and $5.7 \mathrm{GHz}$ bands is presented. The antenna consists of two substrate layers with an electromagnetically coupled low-band patch in the middle layer and a probe-fed dual-band patch on the top layer. The impedance bandwidths (voltage standing wave ratio $($ VSWR $)<2.5)$ for the three frequency bands are 112,118 and $427 \mathrm{MHz}$ with $3 \mathrm{~dB}$ axial-ratio bandwidths of 15,44 and $36 \mathrm{MHz}$, respectively. The peak gains across the operating bands are $4.2,5.5$ and $4 \mathrm{dBic}$, respectively.

Introduction: Circularly polarised antennas are widely used in wireless communication systems due to advantages of immunity to polarisation mismatch and resilience to multipath fading. Many dual-band circularly polarised antennas employing two-layer substrates have been reported [1-4] by using stacked patches with an aperture-coupled feed network [1] or a two-layer-coupled square patch with U-shaped slot [2]. Single-layer single-feed patch antennas for dual-band circular polarisation were proposed by loading Y-shaped or T-shaped slots in a square patch [3] or coupled annular rings with asymmetric cross-slots in the ground plane [4]. Furthermore, in [5], a single-layer patch employing four slots and truncated corners was used to excite dualfrequency dual-sense circular polarisation. However, emerging multimode systems such as wireless fidelity (WiFi) and worldwide interoperability for microwave access (WiMax) demand circularly polarised antennas operating over more than two bands, which are widely disparate. However, some multiband antennas have been reported, such as [6] where a linearly polarised monopole with a modified ground plane achieves triple-band operation at $2.3 \mathrm{GHz} /$ $3.5 \mathrm{GHz} / 5.5 \mathrm{GHz}$. But there are few reports of triple-band circularly polarised antennas with wide frequency ratios using low-profile planar structures.

In this Letter, a novel low-cost triple-band circularly polarised microstrip patch antenna is proposed, which can achieve the wide frequency ratio required for multiband wireless communication systems.

Geometry of proposed antenna: Fig. 1 shows the antenna geometry and coordinate system. The antenna consists of two substrate layers, with the top dual-band patch connected to a $50 \Omega$ SMA feed probe and ground plane on the bottom layer. The middle patch is electromagnetically coupled and has a hole of $2.5 \mathrm{~mm}$ diameter through which the feed probe passes. The two substrate layers are $40 \times 40 \mathrm{~mm}$ with top substrate layer of thickness $3 \mathrm{~mm}, \varepsilon_{\mathrm{r}}=2.33$ and $\tan \delta=0.0018$, and bottom substrate thickness of $1.57 \mathrm{~mm}, \varepsilon_{\mathrm{r}}=4.5$ and $\tan \delta=0.002$. The impedance matching and axial ratio are dependent on key parameters such as the patch dimensions, slot width $(L p 1-L p 2) / 2$, feed probe position and corner truncations. Using the CST Microwave Studio, the optimised parameters were found to be as follows: top patch (Fig. $1 c: L p 1=15 \mathrm{~mm}$, $L p 2=12 \mathrm{~mm}, \Delta S 3=2.5 \mathrm{~mm}, \Delta S 4=3.5 \mathrm{~mm}$ and $\Delta S 5=6.2 \mathrm{~mm})$ and the middle patch (Fig. $1 b: L=25 \mathrm{~mm}, \Delta S 1=2 \mathrm{~mm}$ and $\Delta S 2=4 \mathrm{~mm}$ ). The feed probe location is at the coordinates $(-5 \mathrm{~mm},-1 \mathrm{~mm})$ in the $X o Y$-plane with respect to the origin at the centre of the substrate.

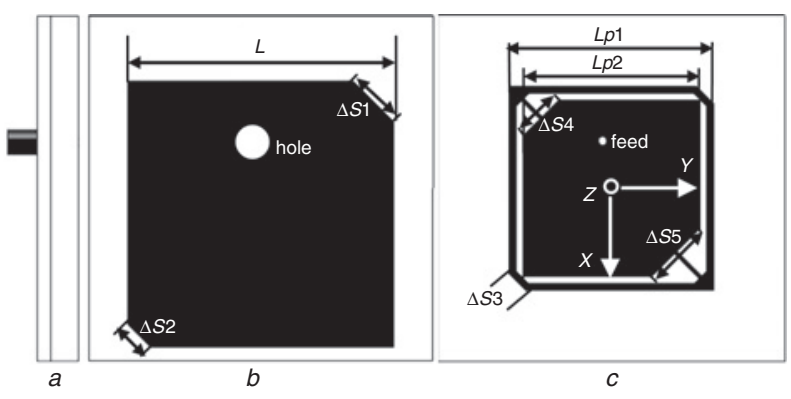

Fig. 1 Configuration of proposed antenna

$a$ Profile

$b$ Middle patch

c Top patch
The modelled surface current distributions are shown in Fig. 2 and it is seen that the electromagnetically coupled middle patch is excited at the low frequency and the other two frequency bands are determined by the probe-fed top patch.

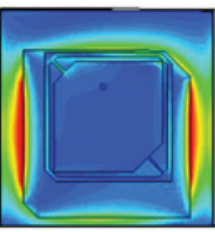

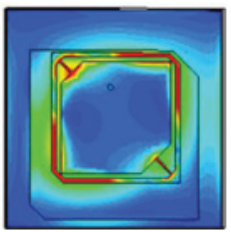

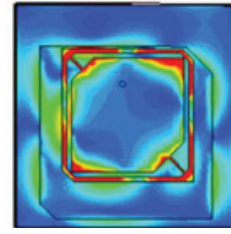

Fig. 2 Surface current distributions for three frequency bands

$a$ Low frequency

$b$ Middle frequency

$c$ High frequency

Circular polarisation is realised at the low band using an asymmetrically cut truncated square patch. Dual-band circular polarisation is provided on the top element by a truncated square patch embedded inside a truncated square outline element. The outer element has symmetrical truncations. For the top dual-band element, both TM01 and TM03 are excited and circular polarisation is produced due to the truncations and slot arrangement $[3,5]$. With proper adjustment of patch sizes, a wide frequency ratio is achieved.

Numerical results for proposed antennas: The optimised antenna was prototyped and measured. Fig. 3 shows the simulated and the measured voltage standing wave ratio (VSWR) to be in good agreement. The measured VSWR exhibits three frequency bands: the lower band from 2.446 to $2.558 \mathrm{GHz}(112 \mathrm{MHz})$, the middle band from 3.466 to $3.584 \mathrm{GHz}(118 \mathrm{MHz})$ and the higher frequency band from 5.635 to $6.062 \mathrm{GHz}(427 \mathrm{MHz})$ for $\mathrm{VSWR}<2.5$.

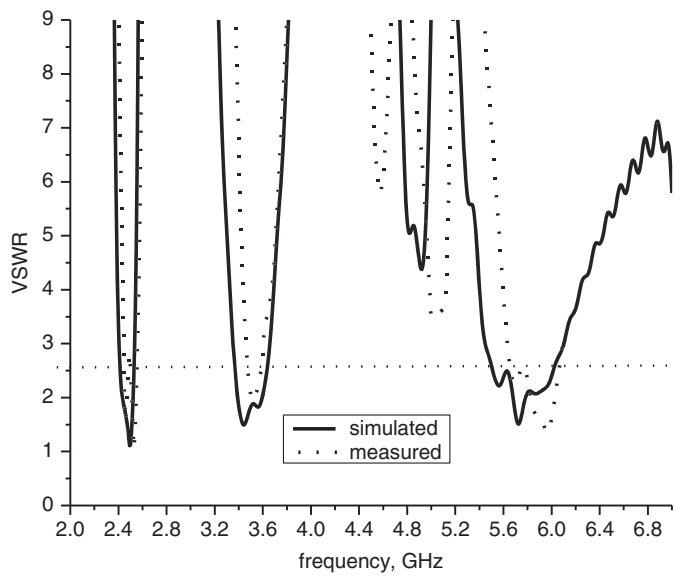

Fig. 3 Measured and simulated VSWUR

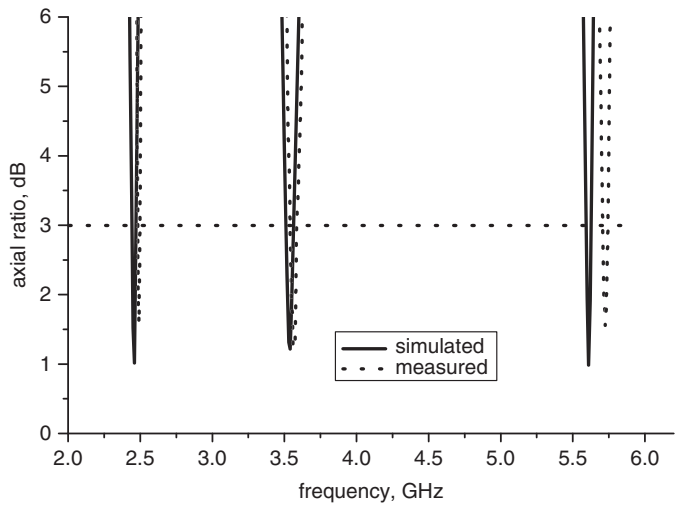

Fig. 4 Axial ratios for proposed antenna

Fig. 4 shows the simulated and the measured axial ratios. The measured axial ratio was $<3 \mathrm{~dB}$ for the lower band from 2.482 to 
$2.497 \mathrm{GHz}(15 \mathrm{MHz})$, the middle band from 3.54 to $3.584 \mathrm{GHz}$ (44 MHz) and the high band from 5.708 to $5.744 \mathrm{GHz}(36 \mathrm{MHz})$.

Fig. 5 shows the measured radiation patterns at frequencies, 2.49, 3.57 and $5.72 \mathrm{GHz}$. The gains are $3.1,5.2$ and $3.7 \mathrm{dBic}$, respectively. The cross-polarisation is better than $15 \mathrm{~dB}$. The middle and higher frequencies exhibit very good front-to-back ratios due to the relatively large ground plane.
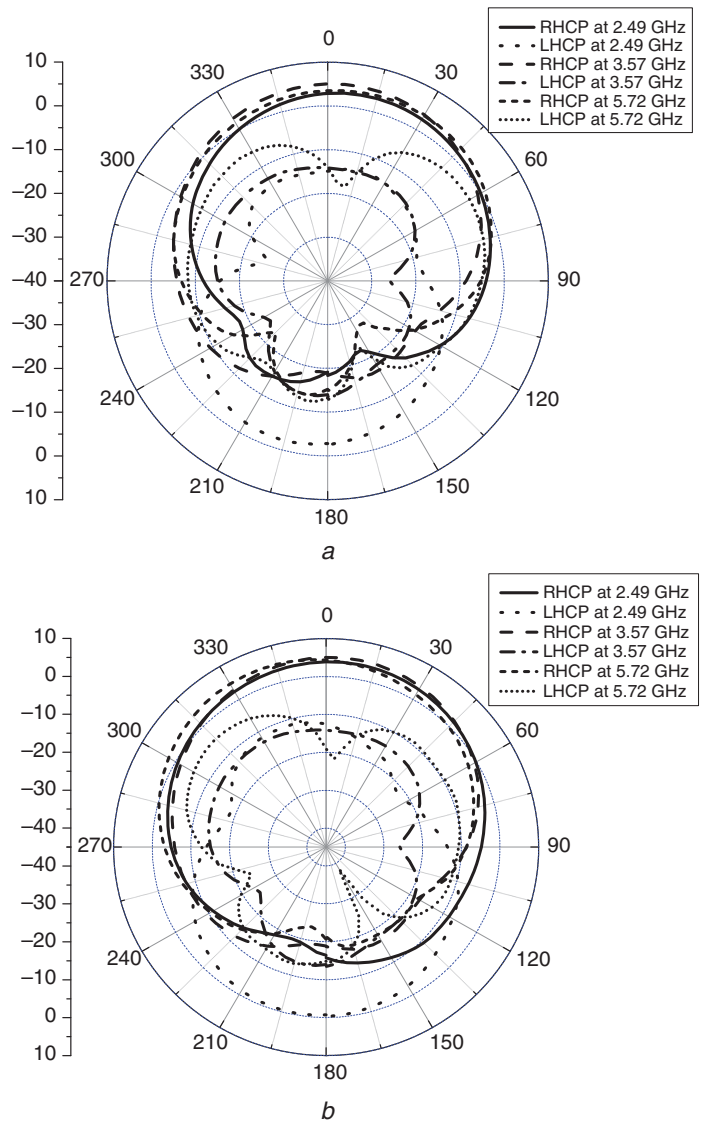

Fig. 5 Measured radiation patterns

a YoZ plane

$b X o Z$ plane

Fig. 6 shows the measured peak gain to be better than $3 \mathrm{dBic}$ across the whole operational frequency range.

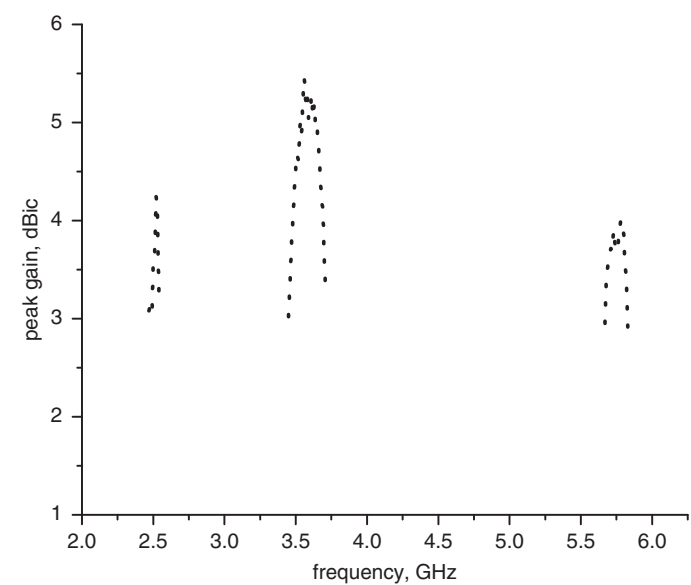

Fig. 6 Measured peak gain for proposed antenna
Conclusion: A novel low-profile triple-band circularly polarised antenna is presented. The wide circularly polarised frequency ratio is achieved by appropriate choice of patch sizes, feed arrangement and slot shapes. The proposed antenna is suitable for application in multiband wireless communications including RFID, WiFi and WiMax.

(C) The Institution of Engineering and Technology 2014

28 August 2014

doi: $10.1049 / \mathrm{el} .2014 .3103$

One or more of the Figures in this Letter are available in colour online.

X.L. Bao and M.J. Ammann (Antenna \& High Frequency Research Centre, School of Electrical and Electronic Engineering, Dublin Institute of Technology, Dublin, Ireland)

E-mail: xiulong.bao@dit.ie

\section{References}

1 Pozar, D.M., and Duffy, S.M.: 'A dual-band circularly polarized aperture-coupled stacked microstrip antenna for global positioning satellite', IEEE Trans. Antennas Propag., 1997, 45, (11), pp. 1618-1625

2 Nayeri, P., Lee, K.F., Elsherbeni, A.Z., and Yang, F.: 'Dual-band circularly polarized antennas using stacked patches with asymmetric U-Slots', IEEE Antennas Wirel. Propag. Lett., 2011, (10), pp. 492-495

3 Yang, K.P., and Wong, K.L.: 'Dual-band circularly-polarized square microwave antenna', IEEE Trans. Antennas Propag., 2011, 59, (11), pp. 4209-4214

4 Bao, X.L., and Ammann, M.: 'Dual-frequency circularly-polarized patch antenna with compact size and small frequency ratio', IEEE Trans. Antennas Propag., 2007, 55, (7), pp. 2104-2107

5 Beddeleem, G., Ribero, J.M., Kossiavas, G., Staraj, R., and Fond, E. 'Dual-frequency circularly polarized antenna', Microw. Opt. Technol. Lett., 2008, 50, (1), pp. 177-180

6 Verma, S., and Kumar, P.: 'Compact triple-band antenna for WiMAX and WLAN applications', Electron. Lett., 2014, 50, (7), pp. 484-486 